\title{
Prognostic value of PAM50 and risk of recurrence score in patients with early- stage breast cancer with long-term follow-up
}

Hege O. Ohnstad ${ }^{1 *}$, Elin Borgen², Ragnhild S. Falk³, Tonje G. Lien ${ }^{4}$, Marit Aaserud $^{2}$, My Anh T. Sveli², Jon A. Kyte ${ }^{1}$, Vessela N. Kristensen ${ }^{4,5}$, Gry A. Geitvik ${ }^{4}$, Ellen Schlichting ${ }^{6}$, Erik A. Wist ${ }^{7}$, Therese Sørlie ${ }^{4}$, Hege G. Russnes ${ }^{2,7}$ and Bjørn Naume ${ }^{1,7}$

\begin{abstract}
Background: The aim of this study was to investigate the prognostic value of the PAM50 intrinsic subtypes and risk of recurrence $(R O R)$ score in patients with early breast cancer and long-term follow-up. A special focus was placed on hormone receptor-positive/human epidermal growth factor receptor 2-negative (HR+/HER2-) pNO patients not treated with chemotherapy.

Methods: Patients with early breast cancer $(n=653)$ enrolled in the observational Oslo1 study (1995-1998) were followed for distant recurrence and breast cancer death. Clinicopathological parameters were collected from hospital records. The primary tumors were analyzed using the Prosigna ${ }^{\circledR}$ PAM50 assay to determine the prognostic value of the intrinsic subtypes and ROR score in comparison with pathological characteristics. The primary endpoints were distant disease-free survival (DDFS) and breast cancer-specific survival (BCSS).
\end{abstract}

Results: Of 653 tumors, 52.2\% were classified as luminal A, 26.5\% as luminal B, 10.6\% as HER2-enriched, and 10.7\% as basal-like. Among the HR+/HER2 - patients $(n=476), 37.8 \%$ were categorized as low risk by ROR score, $22.7 \%$ as intermediate risk, and 39.5\% as high risk. Median follow-up durations for BCSS and DDFS were 16.6 and 7.1 years, respectively. Multivariate analysis showed that intrinsic subtypes (all patients) and ROR risk classification (HR+/HER2patients) yielded strong prognostic information. Among the HR+/HER2- pNO patients with no adjuvant treatment $(n=231), 53.7 \%$ of patients had a low ROR, and their prognosis at 15 years was excellent (15-year BCSS 96.3\%). Patients with intermediate risk had reduced survival compared with those with low risk $(p=0.005)$. In contrast, no difference in survival between the low- and intermediate-risk groups was seen for HR+/HER2- pNO patients who received tamoxifen only. Ki-67 protein, grade, and ROR score were analyzed in the unselected, untreated pT1pN0 HR+/HER2- population $(n=171)$. In multivariate analysis, ROR score outperformed both Ki-67 and grade. Furthermore, $55 \%$ of patients who according to the PREDICT tool (http://www.predict.nhs.uk/) would be considered chemotherapy candidates were ROR low risk (33\%) or luminal A ROR intermediate risk (22\%).

Conclusions: The PAM50 intrinsic subtype classification and ROR score improve classification of patients with breast cancer into prognostic groups, allowing for a more precise identification of future recurrence risk and providing an improved basis for adjuvant treatment decisions. Node-negative patients with low ROR scores had an excellent outcome at 15 years even in the absence of adjuvant therapy.

Keywords: Breast cancer, PAM50, Risk of recurrence, Patient stratification, Follow-up

\footnotetext{
* Correspondence: Hege.Oma.Ohnstad@ous-hf.no

'Division of Cancer Medicine, Department of Oncology, Oslo University

Hospital, Postbox 4953 Nydalen, 0424 Oslo, Norway

Full list of author information is available at the end of the article
} 


\section{Background}

Breast cancer survival has improved during the last two decades because of both early detection and improved treatment strategies such as biomarker-defined therapy (i.e., adjuvant endocrine treatment and trastuzumab) along with chemotherapy for high-risk patients. However, the risk of relapse varies substantially on the basis of individual disease [1]. Differences in clinical behavior among patients with early breast cancer were also paralleled at a molecular level, and the "intrinsic" subtypes, later refined into the PAM50 classification, capture biological traits and are recognized as robust subtypes [2, 3]. In line with the increased body of evidence for improved clinical classification using molecular profiling, classifiers such as the PAM50 intrinsic subtypes and risk of recurrence (ROR) score generated from the expression of the 50 genes (Prosigna ; NanoString Technologies, Seattle, WA, USA) have recently been included in recommendations for decisions on adjuvant systemic treatment for pNO hormone receptor-positive/human epidermal growth factor receptor 2-negative (HR+/HER2-) breast cancer $[4,5]$. Several studies have also emphasized the impact of PAM50 subtypes and ROR scores in assessment of late distant recurrence after endocrine treatment [6, 7]. A number of gene assays have been developed to predict outcomes beyond standard clinicopathological variables, two of which (Oncotype DX, Genomic Health, Redwood City, CA, USA; and MammaPrint, Agendia, Irvine, CA, USA) are currently being evaluated in large, prospective, randomized trials. Results after 5 years with endocrine treatment alone show very low rates of recurrence in HR+/HER2-, axillary lymph node-negative ( $\mathrm{pN} 0$ ) patients with favorable gene expression $[8,9]$. Comparison of multiparameter tests in retrospective analyses, including the prognostic signatures Clinical Treatment Score (CTS), four immunohistochemical markers (IHC4 score), oncotype recurrence score (RS), EndoPredict score (EPclin), Breast Cancer Index (BCI), and ROR score [10-16], indicate that EPclin and ROR score may be the strongest predictors of distant recurrence in both node-positive and node-negative $\mathrm{HR}+$ patients with breast cancer. Particularly, EPclin and ROR score appear to be promising identifiers of patients at low risk for distant recurrence, with a potential to outperform CTS [17]. Hence, these classifiers may identify patients who may be spared adjuvant chemotherapy and be sufficiently treated with endocrine treatment only, unlike those classified as having a high risk of relapse.

The use of molecular profiling has not yet been widely established in all countries, and additional studies may provide important information regarding long-term survival and how to include the tests in clinical routine. The aim of the present study was to evaluate the long-term prognostic value of the
PAM50 intrinsic subtypes, and especially the ROR score, in patients with HR+/HER2- early-stage breast cancer after extended follow-up.

\section{Methods}

\section{Patients and tumor characteristics}

Consecutive patients with early breast cancer from the observational Oslo Micrometastasis Project (the Oslo1 study) ( $n=920)$ who were enrolled at Oslo University Hospital $(n=778)$ and for whom there were available formalin-fixed, paraffin-embedded (FFPE) samples from the primary tumor $(n=760)$ were included in the present study (Fig. 1). Patients with tumors determined to be benign or with in situ histology $(n=45)$ were excluded, as were patients who received neoadjuvant treatment $(n=13)$ or had metastasis at diagnosis $(n=8)$. Furthermore, 41 patients were excluded because their samples did not pass the quality threshold for the PAM50/ROR analysis. The patients were included from 1995 to 1998 and were all treated as per national recommendations. At the time of enrollment, patients with pT1pN0 (regardless of grade) and pT2pN0 grade 1 received no adjuvant treatment (neither tamoxifen [if $\mathrm{HR}+]$ nor chemotherapy), whereas those with pT2pN0G2-3, pT3-4pN0 (regardless of grade) or pN1-3 received systemic treatment (i.e., tamoxifen and/or chemotherapy), except for HR- patients aged $\geq 65$ years. Chemotherapy (CMF regimen, which consisted of six cycles [every 3 weeks] of intravenous cyclophosphamide $600 \mathrm{mg} / \mathrm{m}^{2}$, methotrexate $40 \mathrm{mg} / \mathrm{m}^{2}$, and fluorouracil $600 \mathrm{mg} / \mathrm{m}^{2}$ ) was administered if patients were $<55$ years of age or aged $\leq 65$ years with HR- tumors. Patients with $\mathrm{HR}+$ disease received tamoxifen for 5 years.

Clinical and histopathological parameters were collected from hospital records. HR was defined as positive if $\geq 10 \%$ of the cells were stained positive by estrogen receptor (ER) and/or progesterone receptor (PgR). Amplification of the HER2 gene was assessed as previously described [18]. Ki-67 labeling index (as hot spot) was determined (retrospectively) in the pT1pN0 patients as described in Additional file 1.

Information on follow-up and vital status was obtained through review of medical records and data from the Norwegian death cause registry (provided by the Norwegian Institute of Public Health). We considered a death related to breast cancer when breast cancer was the underlying cause of death. The last obtainable update of disease relapse was completed in 2005. The follow-up for breast cancer death was completed on December 31, 2014.

\section{PAM50 assay description and ROR calculation}

RNA was extracted (High Pure FFPET RNA Isolation Kit, catalogue number 06650775001; Roche Applied 


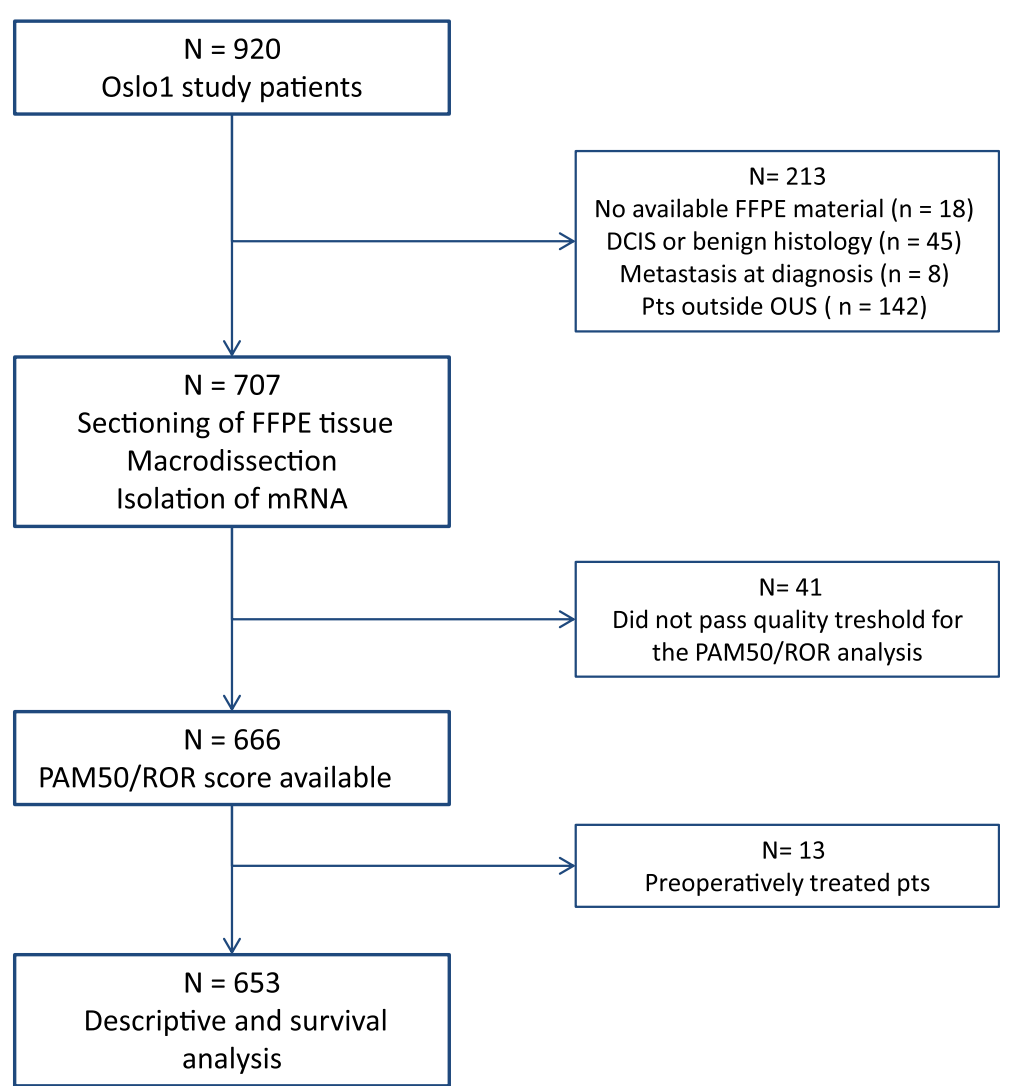

Fig. 1 Overview of patients included in the analysis. DCIS Ductal carcinoma in situ, FFPE Formalin-fixed, paraffin-embedded, mRNA Messenger RNA, Os/o1 Oslo Micrometastasis Project, OUS Oslo University Hospital, ROR Risk of recurrence

Science, Penzberg, Germany) from FFPE blocks of breast cancer tumor tissue, and expression of the PAM50 genes was analyzed using the nCounter Analysis System (NanoString Technologies). Data were analyzed using the Prosigna algorithm (NanoString Technologies) converted into intrinsic subtype calls, ROR scores, and risk categories as previously described $[19,20]$. Tumors with ROR scores $\leq 40$ were categorized as low ROR, 41-60 as intermediate risk if $\mathrm{pN0}$ and high risk if $\mathrm{pN} 1$, and $>60$ as high risk. All patients with pN2-3 were categorized as high risk, regardless of ROR score.

\section{Statistics}

Descriptive statistics were used for patients and tumor characteristics, and results are presented as frequencies and proportions. The patients studied were selected from an observational study with distant disease-free survival (DDFS) and breast cancerspecific survival (BCSS) as primary outcomes [21]. DDFS was defined as time from surgery to any distant metastasis, and BCSS was defined as time from surgery to breast cancer-related death. The patients were followed longitudinally from the date of surgery to the date of distant metastasis or date of death, or to the end of follow-up if no event had occurred. In the survival analyses, patients were censored at 15year follow-up for breast cancer death and 8-year follow-up for distant metastasis (80\% of maximal follow-up time). Survival was presented in KaplanMeier plots based on log-rank tests. Analyses were performed across all patients, as well as according to subgroups by administration of systemic treatment, HR/HER2 status, PAM50 intrinsic subtypes, and ROR score risk categories.

Uni- and multivariate Cox regression models were conducted to evaluate the impact of the prognostic factors on DDFS and BCSS. Risk estimates are presented as hazard ratios with $95 \% \mathrm{CI}$. The assumption of proportional hazards was met on the basis of analysis of Schoenfeld residuals. No multicollinearity between the independent variables (tested by variance inflation factor analysis) was found.

All $p$ values were two-tailed, and $p<0.05$ was regarded as significant. However, owing to the large number of subgroup analyses, the significance level of the log-rank tests was set to $p<0.005$. Data analysis was performed using Stata version 14 software (StataCorp, College Station, TX, USA). 


\section{Results}

\section{Patient/tumor characteristics and PAM50 subtype/ROR} score

An overview of the selection of patients included in the present study $(n=653)$ is presented in Fig. 1. Patient characteristics are listed in Table 1. Median age at inclusion was 57.7 years (range 27.5-93.0). A total of 331 patients $(50.7 \%)$ received no adjuvant treatment, 164 (25.1\%) received tamoxifen only, and 158 (24.2\%) received CMF with or without tamoxifen. By PAM50 gene expression profiling, tumors were classified into subtypes as luminal A (52.2\%), luminal B (26.5\%), HER2-enriched (10.6\%), and basal-like (10.7\%). Among the $\mathrm{HR}+/$ HER $2-$ patients, $37.8 \%$ were categorized as low risk by ROR score, $22.7 \%$ as intermediate risk, and $39.5 \%$ as high risk (Table 2). As expected, luminal A subtype and low ROR score were more frequent among the node-negative than among the node-positive patients. Moreover, the majority of the tumors categorized as $\mathrm{HR}+/ \mathrm{HER} 2-$ by immunohistochemistry were of the luminal A or B subtype (94\%) (Additional file 1: Figure S1). Finally, luminal A tumors showed markedly lower ROR scores than the other three subtypes (Additional file 1: Figure S2).

\section{PAM50 subtype/ROR score classification and clinical outcome}

The median follow-up times for BCSS and DDFS were 16.6 years (range $0.4-19.7)$ and 7.1 years $(0.1-10.4)$, respectively. Overall, 164 patients $(25.1 \%)$ died of breast cancer. The 5- and 10-year DDFS rates were 83.8\% (95\% CI 80.6-86.5\%) and 74.2\% (95\% CI 69.3-78.4), respectively, and the 10- and 15-year BCSSs were 79.6\% (95\% CI 76.2-82.5\%) and 75.0\% (95\% CI 71.3-78.3\%).

Survival analyses according to PAM50 subtypes showed that patients with the luminal A subtype had favorable BCSS and DDFS, particularly in the subgroup of patients who did not receive adjuvant systemic treatment (Fig. 2). The HER2-enriched patients (who did not receive HER2-directed treatment) had the worst outcomes. The PAM50 subtype classification also separated and refined clinical outcomes for patients within HR/HER2 subgroups (Additional file 1: Figure S3). Multivariate analysis confirmed the prognostic impact of this classification, showing that patients with luminal A tumors had improved BCSS and DDFS compared with patients with the other subtypes (Additional file 2: Table S1).

Among the HR+/HER2- patients, the ROR risk classification separated patients with different BCSS and DDFS survival (see Fig. 3 and Additional file 1: Figure S4 for separate analysis of node-negative and node-positive patients). In multivariate analysis accounting for $\mathrm{pT}, \mathrm{pN}$, grade, age, and systemic treatment, ROR score was an
Table 1 Baseline characteristics

\begin{tabular}{|c|c|c|}
\hline & No. of patients & Percent \\
\hline All patients & 653 & 100 \\
\hline \multicolumn{3}{|l|}{ Age at inclusion } \\
\hline$\geq 55$ years & 271 & 41.5 \\
\hline$<55$ years & 382 & 58.5 \\
\hline \multicolumn{3}{|l|}{ T status } \\
\hline pT1 & 377 & 57.8 \\
\hline pT2 & 234 & 35.8 \\
\hline pT3-4 & 26 & 4.0 \\
\hline pTX & 16 & 2.5 \\
\hline \multicolumn{3}{|l|}{$\mathrm{N}$ status } \\
\hline pNO & 419 & 64.2 \\
\hline pN1 & 136 & 20.8 \\
\hline $\mathrm{pN} 2$ & 59 & 9.0 \\
\hline pN3 & 23 & 3.5 \\
\hline $\mathrm{pNX}$ & 16 & 2.5 \\
\hline \multicolumn{3}{|l|}{ Histological grade } \\
\hline 1 & 153 & 23.4 \\
\hline$\|$ & 322 & 49.3 \\
\hline III & 177 & 27.1 \\
\hline Missing & 1 & 0.2 \\
\hline \multicolumn{3}{|l|}{ HR status } \\
\hline Positive ( $\geq 10 \%)$ & 512 & 78.4 \\
\hline Negative $(0$ to $<10 \%$ ) & 137 & 21.0 \\
\hline Missing & 4 & 0.6 \\
\hline \multicolumn{3}{|l|}{ HER2 status } \\
\hline Negative & 578 & 88.5 \\
\hline Positive & 71 & 10.9 \\
\hline Missing & 4 & 0.6 \\
\hline \multicolumn{3}{|l|}{ HR/HER2 subclasses } \\
\hline HR+/HER2- & 476 & 72.9 \\
\hline HR+/HER2+ & 36 & 5.5 \\
\hline HR-/HER2+ & 35 & 5.4 \\
\hline HR-/HER2- & 102 & 15.6 \\
\hline Missing & 4 & 0.6 \\
\hline \multicolumn{3}{|l|}{$\mathrm{Ki}-67(n=218)^{\mathrm{a}}$} \\
\hline$<15 \%$ & 103 & 47.2 \\
\hline $15-30 \%$ & 77 & 35.3 \\
\hline$\geq 30 \%$ & 38 & 17.4 \\
\hline \multicolumn{3}{|l|}{ Histological subtype } \\
\hline Ductal & 499 & 76.4 \\
\hline Lobular & 121 & 18.5 \\
\hline Other & 33 & 5.1 \\
\hline \multicolumn{3}{|l|}{ Adjuvant treatment } \\
\hline No adjuvant & 331 & 50.7 \\
\hline Tamoxifen only & 164 & 25.1 \\
\hline CMF with or without Tam & 158 & 24.2 \\
\hline
\end{tabular}

Abbreviations: CMF Cyclophosphamide, methotrexate, fluorouracil, HER2 Human epidermal growth factor receptor 2, HR Hormone receptor, TAM Tamoxifen aKi-67 analysis (hot spot) of the pT1pN0 patients, 171 of whom were HR+/HER2- 
Table 2 Frequency distribution of PAM50 intrinsic subtypes and risk of recurrence score

\begin{tabular}{|c|c|c|c|c|c|c|}
\hline & \multicolumn{2}{|l|}{ All patients } & \multicolumn{2}{|c|}{ Node-negative patients ${ }^{\mathrm{a}}$} & \multicolumn{2}{|c|}{ Node-positive patients ${ }^{\mathrm{a}}$} \\
\hline & No. of patients & $\%$ & No. of patients & $\%$ & No. of patients & $\%$ \\
\hline All patients & 653 & 100 & 419 & 64.2 & 218 & 33.4 \\
\hline \multicolumn{7}{|c|}{ PAM50 intrinsic subtype } \\
\hline Luminal A & 341 & 52.2 & 240 & 57.3 & 95 & 43.6 \\
\hline Luminal B & 173 & 26.5 & 103 & 24.6 & 65 & 29.8 \\
\hline HER2enriched & 69 & 10.6 & 30 & 7.2 & 38 & 17.4 \\
\hline Basal-like & 70 & 10.7 & 46 & 11.0 & 20 & 9.2 \\
\hline ROR score, median & 51 & & 46 & & 56 & \\
\hline HR+/HER2- patients & 476 & 100 & 318 & 66.8 & 149 & 31.3 \\
\hline \multicolumn{7}{|c|}{ ROR risk score classification } \\
\hline Low risk & 180 & 37.8 & 145 & 45.6 & 33 & 22.1 \\
\hline Intermediate risk & 108 & 22.7 & 104 & 32.7 & - & - \\
\hline High risk & 188 & 39.5 & 69 & 21.7 & 116 & 77.9 \\
\hline ROR score, median & 46 & & 42 & & 50 & \\
\hline
\end{tabular}

Abbreviations: HER2 Human epidermal growth factor receptor 2, HR Hormone receptor, ROR Risk of recurrence

${ }^{a}$ Nine patients were classified as pNX

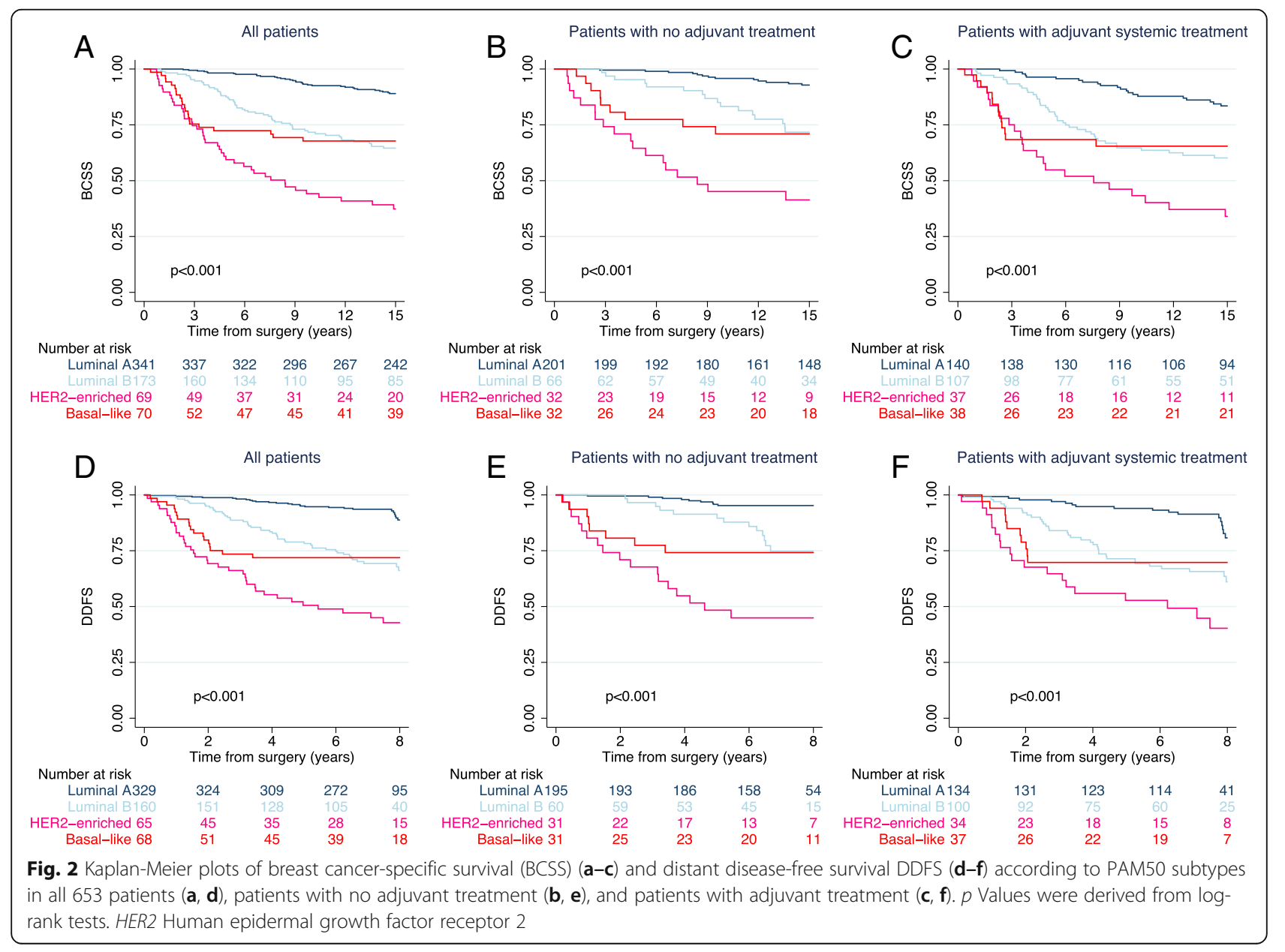




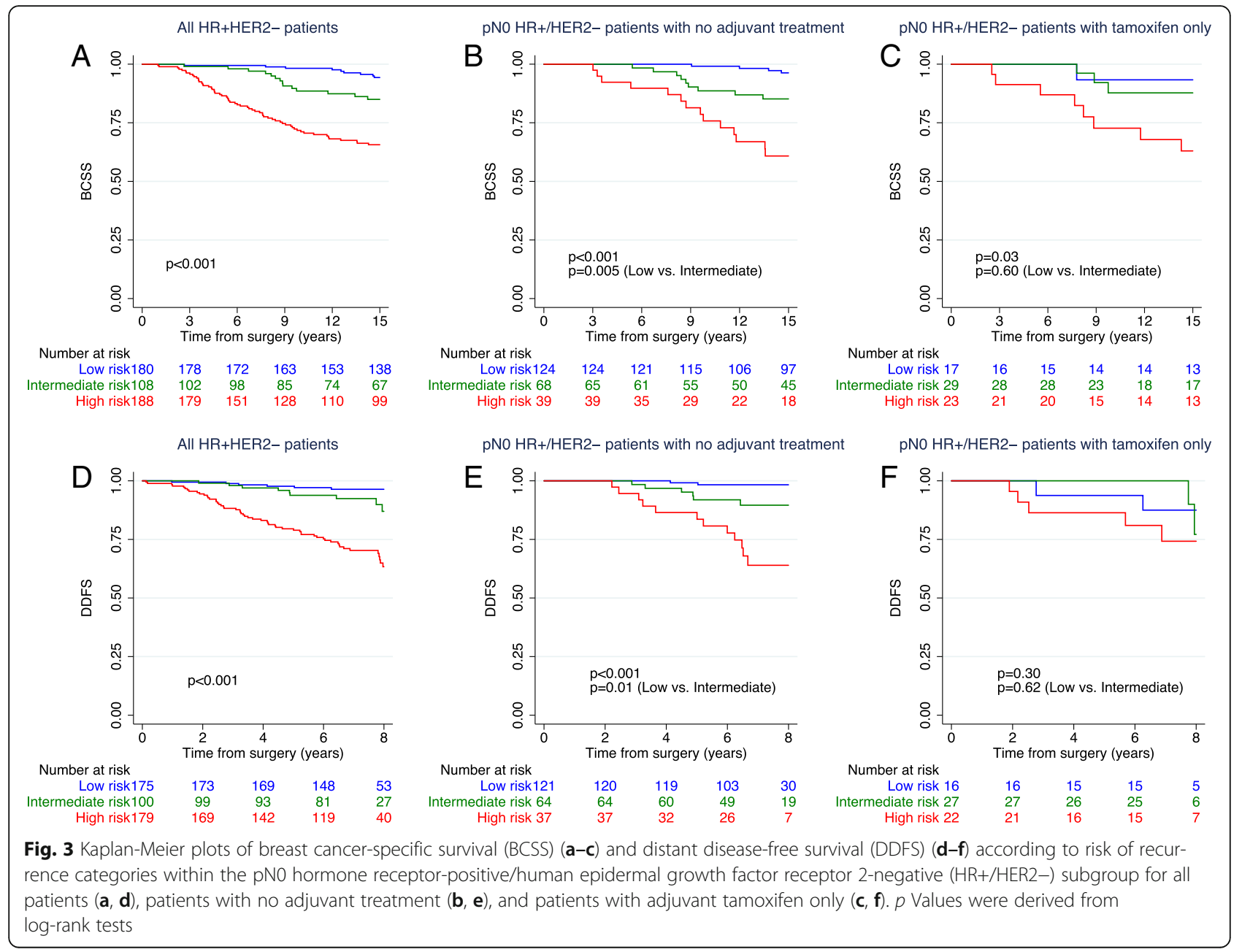

independent prognostic factor (Table 3). Patients classified as ROR high risk had a markedly increased risk of breast cancer death and distant metastasis compared with patients with ROR low risk (hazard ratio 4.69, 95\% CI 2.08-10.55; and hazard ratio 6.82, 95\% CI 2.6217.81, respectively) (Table 3). The hazard ratio for BCSS among patients with intermediate risk versus low risk was 2.25 (95\% CI 0.94-5.41, $p=0.070$ ).

\section{ROR score and clinical outcome within the node negative} HR+/HER2- subgroups

Because only $18(5.7 \%)$ of the 318 node-negative HR +/HER2- patients received chemotherapy and 231 (72.6\%) received neither chemotherapy nor endocrine treatment, this subgroup of patients was studied in more detail to unveil the impact of the ROR categories on long-term risk of distant disease and breast cancer death without use of chemotherapy with or without endocrine treatment. Among those who did not receive any adjuvant treatment $(n=231), 53.7 \%, 29.4 \%$, and $16.9 \%$ of the patients were assigned to the low-, intermediate-, and high-risk ROR risk groups, respectively. Patients with low ROR risk had an excellent prognosis at 15 years (15-year BCSS 96.3\%, 95\% CI 90.4-98.6\%), whereas the intermediate- and high-risk groups had reduced survival (BCSS 85.2\%, 95\% CI 73.4-92.0\%; and 60.8\%, 95\% CI 42.8-74.7\%, respectively) (Fig. 3). There was a difference in BCSS for patients in ROR low-risk versus ROR intermediate-risk categories $(p=0.005)$. In contrast, among patients who received tamoxifen only $(n=69)$, no difference in survival between the low- and intermediate-risk groups was observed $(p=0.60)$. Similar results were found when the analysis was restricted to the luminal A pNO HR+/HER2- patients (Additional file 1: Figure S5). Both the untreated and tamoxifen-treated, node-negative, HR+/HER2- patients classified as ROR high risk appeared to have reduced survival (Fig. 3).

\section{ROR versus Ki-67 analysis in node-negative HR+/HER2- pT1 subgroup}

The Ki-67 labeling indexes (hot spot) were previously determined for the patients with HR+/HER2- pT1pN0 tumors, representing an unselected subgroup of untreated patients (who were not recommended any adjuvant 
Table 3 Multivariate analysis of distant disease-free survival and breast cancer-specific survival for the HR+/HER2- patients, including risk of recurrence risk classification

\begin{tabular}{|c|c|c|c|c|c|c|}
\hline & \multicolumn{3}{|c|}{ DDFS $(n=441)$} & \multicolumn{3}{|c|}{$\operatorname{BCSS}(n=461)$} \\
\hline & Hazard ratio & $95 \% \mathrm{Cl}$ & $\overline{p \text { Value }}$ & Hazard ratio & $95 \% \mathrm{Cl}$ & $p$ Value \\
\hline \multicolumn{7}{|l|}{$\overline{\mathrm{pT}}$} \\
\hline 1 & 1 & & & 1 & & \\
\hline 2 & 1.70 & $0.97-3.00$ & 0.065 & 1.52 & $0.91-2.52$ & 0.107 \\
\hline $3-4$ & 2.30 & $0.86-6.14$ & 0.097 & 2.41 & $0.99-4.21$ & 0.054 \\
\hline \multicolumn{7}{|l|}{ Grade } \\
\hline । & 1 & & & 1 & & \\
\hline$\|$ & 1.47 & $0.69-3.13$ & 0.319 & 1.68 & $0.82-3.42$ & 0.156 \\
\hline III & 1.39 & $0.56-3.42$ & 0.474 & 2.35 & $1.04-5.35$ & 0.041 \\
\hline \multicolumn{7}{|l|}{$\mathrm{pN}$} \\
\hline 0 & 1 & & & 1 & & \\
\hline 1 & 1.31 & $0.61-2.81$ & 0.492 & 1.22 & $0.61-2.45$ & 0.578 \\
\hline $2-3$ & 2.27 & $1.04-4.98$ & 0.040 & 2.04 & $0.99-4.21$ & 0.054 \\
\hline \multicolumn{7}{|l|}{ Age } \\
\hline$<55$ years & 1 & & & 1 & & \\
\hline$\geq 55$ years & 0.58 & $0.30-1.11$ & 0.102 & 0.63 & $0.36-1.14$ & 0.130 \\
\hline \multicolumn{7}{|l|}{ Systemic treatment } \\
\hline No & 1 & & & 1 & & \\
\hline Tam & 0.99 & $0.48-2.05$ & 0.982 & 1.06 & $0.56-2.03$ & 0.854 \\
\hline Chemotherapy \pm Tam & 0.40 & $0.16-1.02$ & 0.055 & 0.48 & $0.21-1.10$ & 0.084 \\
\hline \multicolumn{7}{|l|}{ ROR score } \\
\hline Low & 1 & & & 1 & & \\
\hline Intermediate & 2.25 & $0.77-6.60$ & 0.137 & 2.25 & $0.94-5.41$ & 0.070 \\
\hline High & 6.82 & $2.62-17.81$ & $<0.001$ & 4.69 & $2.08-10.55$ & $<0.001$ \\
\hline
\end{tabular}

Abbreviations: BCSS Breast cancer-specific survival, DDFS Distant disease-free survival, HER2 Human epidermal growth factor receptor $2, H R$ Hormone receptor, $R O R$ Risk of recurrence, TAM Tamoxifen

treatment at the time of inclusion) [18]. The correlation between Ki-67 expression and ROR score for the HR +/HER2- tumors is shown in Additional file 1: Figure S6. Although the observed correlation was fair, the degree of variability poses a challenge in applying strict cutoff values. Multivariate analysis of BCSS and DDFS, including ROR score, Ki-67 (as both continuous and categorical variables), and histologic grade, revealed that only ROR score remained a significant prognostic factor (Table 4).

\section{Treatment alteration analysis based on use of ROR} classification in node-negative HR+/HER2- $\mathrm{pT} 1$ subgroup We analyzed ROR classification among the 171 HR+/HER2pT1pN0 patients and compared the results with the estimated benefit of chemotherapy according to the web-based algorithm PREDICT (www.predict.nhs.uk), which is based on standard histopathological criteria. For nine patients, the exact tumor size was missing and thus was excluded from the PREDICT analysis. As presented in Table 5, 33\% of the patients who had an absolute chemotherapy benefit $\geq 3 \%$ according to PREDICT were classified as ROR low risk. In addition, 22\% were classified as luminal A with ROR intermediate risk, and $8 \%$ of the patients with $<3 \%$ chemotherapy benefit were classified as luminal B with either ROR intermediate or high risk.

\section{Discussion}

In this study of patients with early-stage breast cancer with 17 years follow-up, the PAM50 subtypes and ROR scores clearly improved the prognostic classification beyond current clinicopathological parameters. Importantly, we were able to study an unselected subgroup of node-negative patients who did not receive any adjuvant treatment. We identified a large group of patients with node-negative HR+/HER2- disease with an excellent prognosis and questionable benefit of adjuvant chemotherapy. A subgroup of these patients may also have limited advantage of endocrine treatment. The ROR score was superior to histological grade and Ki-67 
Table 4 Multivariate analysis of distant disease-free survival for the HR+/HER2- pT1pN0 patients, including Ki-67 and risk of recurrence score as continuous and categorical variables

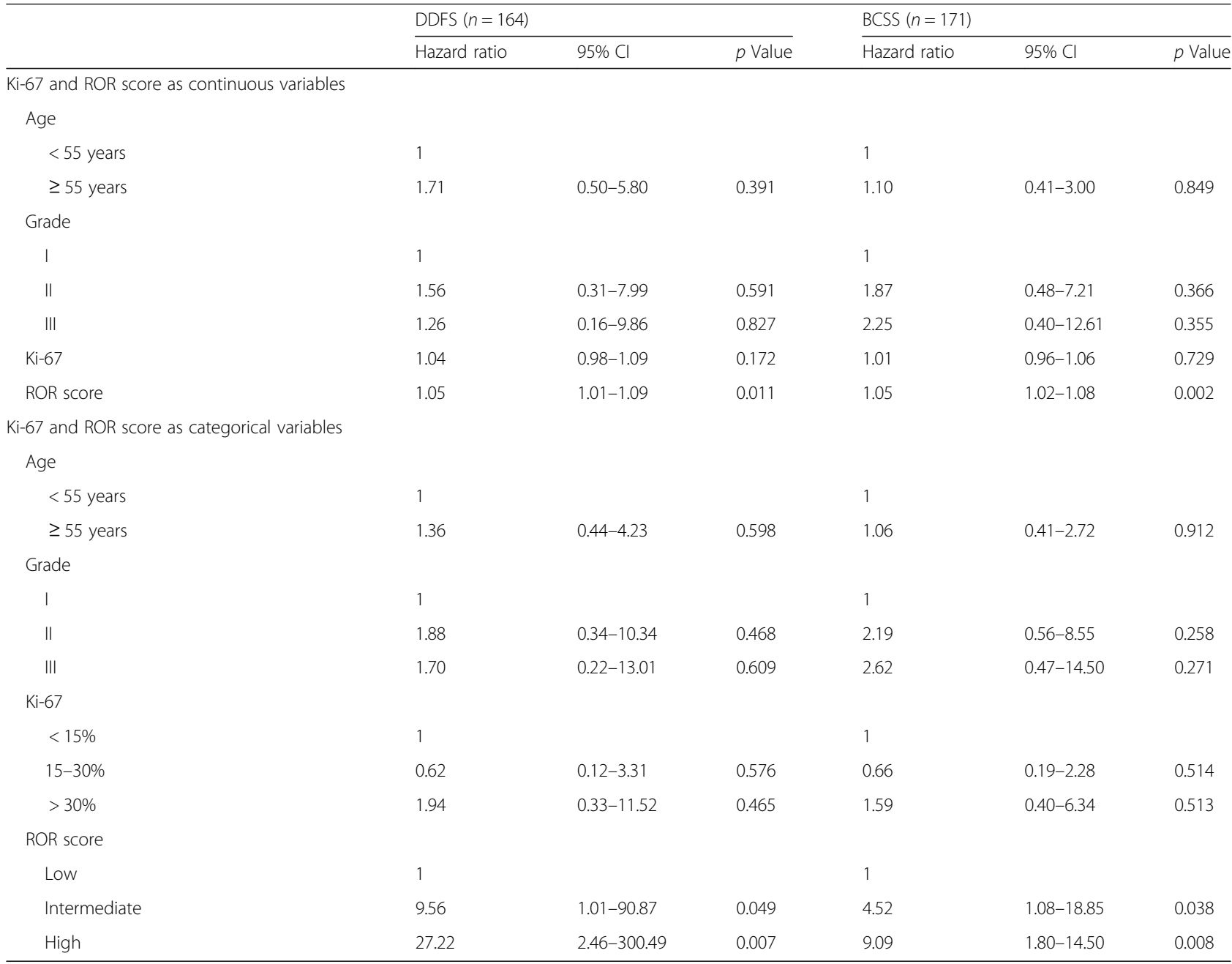

Abbreviations: BCSS Breast cancer-specific survival, DDFS Distant disease-free survival, HER2 Human epidermal growth factor receptor 2, HR Hormone receptor, ROR Risk of recurrence

Table 5 Treatment benefit according to PREDICT model versus risk of recurrence score for patients with HR+/HER2- pT1pNO disease

\begin{tabular}{|c|c|c|c|c|}
\hline & \multicolumn{3}{|c|}{$\begin{array}{l}\text { PREDICT model (absolute } \\
\text { benefit of chemotherapy, } \\
\text { 10-year OS) } \\
\end{array}$} & \multirow[b]{2}{*}{ No. of patients } \\
\hline & $<3 \%$ & $3-5 \%$ & $\geq 5 \%$ & \\
\hline \multicolumn{5}{|l|}{ ROR score } \\
\hline Low & 57 & 30 & 0 & 87 \\
\hline Intermediate, Luminal A & 8 & 18 & 2 & 16 \\
\hline Intermediate, Luminal B & 4 & 12 & 3 & 19 \\
\hline High & 2 & 12 & 14 & 28 \\
\hline Total & 71 & 72 & 19 & 162 \\
\hline
\end{tabular}

Abbreviations: HER2 Human epidermal growth factor receptor 2, HR Hormone receptor, OS Overall survival, ROR Risk of recurrence

Ki-67 positivity for the PREDICT model (http://www.predict.nhs.uk/) is defined as $>10 \%$ of tumor cells staining positive (average counting). Adjusting for $\mathrm{Ki}-$ 67 labeling index as a hot spot in our study, Ki-67 positivity for the PREDICT analysis was defined as $>20 \%$ of tumor cells staining positive [46] labeling index as a prognostic factor. In line with other multigene tests, the refinement in risk classification by the ROR score may help the treating physician and the patient arrive at a balanced decision on adjuvant treatment $[8,22-24]$.

Data are still lacking on the prognostic impact of the ROR score among untreated patients. We were able to study a relatively large group of node-negative HR +/HER2- patients, representing three-fourths of this population, who did not receive any adjuvant systemic treatment (neither tamoxifen nor chemotherapy). About half of these patients were classified in the low ROR risk group and had an excellent long-term prognosis. These results are in line with what was observed in several studies of PAM50 ROR as well as other multigene signatures in HR+/HER2- disease, although the patients in these studies received endocrine treatment [7-9, 12, 13, 15, 25-27]. Together, the available data support 
omission of chemotherapy to node-negative HR+/HER2 - patients with low-risk multiparameter tests.

The recommended use of adjuvant endocrine treatment has changed markedly since the patients were included in the present study. In many guidelines, nearly all $\mathrm{HR}+$ patients are now advised to receive endocrine treatment [4, 5]. However, the patients who did not receive endocrine treatment in our study (any grade pT1pN0 and grade $1 \mathrm{pT} 2 \mathrm{pN} 0$ ) are comparable to such patients diagnosed today because the median tumor size for the entire study population was identical to what was reported on the national level in Norway in 2015 (17 mm) [28, 29]. The excellent prognosis among patients with node-negative HR+/HER2- disease and low ROR scores in this study indicates that a subgroup of these patients is sufficiently treated without adjuvant endocrine therapy. However, we recognize the limited number of patients in the subgroup analyses. Additional data derived from larger untreated (and unselected) patient series to support these results are warranted but difficult to obtain. Delahaye et al. recently reported an ultralow/indolent signature based on the 70-gene signature, identifying a small subgroup of patients not receiving adjuvant treatment who had $100 \% 15$ years of BCSS [30]. Comparison of this ultralow signature with the low-risk ROR score would be of interest. In the clinic, a significant proportion of patients receiving adjuvant endocrine treatment experience a level of side effects that may challenge the individual benefit of the treatment $[31,32]$. Also, poor adherence to/nonpersistence with endocrine treatment has been reported [33]. Because extended adjuvant endocrine treatment recommendations have been introduced to reduce the risk of late recurrence among HR+/HER2- patients, there is also a need for improved selection criteria to better identify candidates for prolonged endocrine treatment $[34,35]$. Recent studies have documented the advantage of using multiparameter tests for improved prognostication after 5 years of endocrine treatment, such as EPclin, $\mathrm{BCI}$, and ROR score [14, 36-39]. Our results support the potential use of such tests for extended adjuvant endocrine treatment decisions. New possibilities for improved prognostication of patients who are candidates for endocrine treatment would support the counseling and treatment decisions for the individual patient by taking into account both side effects and recurrence risk (without any endocrine treatment or extended endocrine treatment) [40].

We observed outcomes similar to those with low ROR score (postmenopausal group) for the nodenegative $\mathrm{HR}+$ /HER2 - patients with intermediate ROR scores receiving adjuvant endocrine treatment only. In contrast, patients in the intermediate-risk group had reduced survival compared with those in the low-risk group when no adjuvant treatment was administered. Although this finding should be interpreted with caution owing to the restricted number of patients, this indicates that endocrine treatment without chemotherapy could be a treatment option also for patients with pNO HR+/HER2- disease with tumors in the intermediate-risk category. In contrast, the results from the ABCSG (Austrian Breast and colorectal Cancer Study Group) and ATAC (Arimidex, Tamoxifen, Alone or in Combination) studies showed reduced DDFS among patients with intermediate-risk ROR scores compared with the low-risk category, all receiving endocrine therapy $[14,25]$. However, a definitive answer to the benefit of chemotherapy for these patients needs a randomized clinical trial. The ongoing OPTIMA trial addresses this issue [41].

In addition to the identification of a large low-risk group, the ROR risk classification also sets apart a highrisk group of patients among the node-negative HR +/HER2 - subgroup. On the basis of current routine classification, high risk of distant recurrence in a fraction of patients expected to have a relatively low recurrence risk is still a concern [42]. Thus, additional prognostic information by ROR score or other multigene test may help clinicians to better select candidates for chemotherapy, especially in doubtful cases.

On the basis of extrapolated analyses using current treatment recommendations for this retrospective population, adding the ROR information to clinical decisionmaking may reduce the use of chemotherapy by at least one-third (Table 5). This is in accordance with the results from the EORTC 10041/BIG 3-04 MINDACT (Microarray in Node-Negative and 1 to 3 Positive Lymph Node Disease May Avoid Chemotherapy) trial [8]. Consequently, a reduction in the unnecessary side effects and a reduced health economic burden are expected, but they merit further validation in prospective clinical trials. Recent publications have also suggested that a 13-47\% change in treatment decisions will be reflected by future cost-effectiveness analyses [22, 40, 43, 44].

A combination of the biomarkers ER, PgR, HER2, and Ki-67 has been used in treatment guidelines, and these entities act as surrogate markers for the molecular breast cancer subtypes [5]. Despite a focus on standardization of these markers (particularly Ki-67), lack of reproducibility is still a concern $[10,45]$. Reports have indicated that the ROR score and intrinsic subtyping are superior to a standardized immunohistochemical classification algorithm (IHC4) [19, 26]. In this study, Ki-67 showed correlation with ROR score, in line with the special weighting of a set of proliferation-associated genes in the ROR score model [26]. Still, the observed variability is large and clearly illustrates that Ki-67 and ROR score are not interchangeable. Importantly, our results show 
that ROR score outperformed Ki-67 and histological grade as a prognostic factor among the pN0 HR+/HER2 - patients. This is also supported by other studies [26].

\section{Conclusions}

Our results support the use of the PAM50 ROR score to improve the classification of patients with breast cancer into prognostic groups, allowing for a more precise identification of future recurrence risks and an improved basis for adjuvant treatment decisions. Patients with nodenegative HR+/HER2 - tumors with low ROR scores can be treated sufficiently without use of chemotherapy, and some may have such a limited systemic relapse risk that one may question the benefit of adjuvant endocrine treatment in individual cases. Patients with intermediate ROR scores (mainly luminal A patients) may represent an additional subgroup with questionable benefit from chemotherapy, but this merits further studies. The PAM50 and Prosigna ${ }^{\circ}$ risk classification may result in a significant reduction in the use of adjuvant chemotherapy.

\section{Additional files}

Additional file 1: Methods. Immunohistochemical analysis for Ki-67. Figure S1. Distribution of PAM50 subtypes within subgroups based on HR and HER2 status. Bars represent percentage of total in each HR/HER2group. Number is displayed on top of the bar. Figure S2. ROR score within each of the PAM50 subtypes for all patients (R statistical software package). Figure S3. Kaplan-Meier plots of BCSS (S3a) and DDFS (S3b) according to HR/HER2 subtypes in all 653 patients (a) and according to PAM50 subtypes within different HR/HER2 (b-e) subgroups. $p$ Values were derived from log-rank tests. Figure S4. Kaplan-Meier plots of BCSS according to ROR categories for node-negative (a) and node-positive (b) HR+/HER2 - patients. $p$ Values were derived from log-rank tests.

Figure S5. Kaplan-Meier plots of BCSS ( $\mathbf{a}$ and $\mathbf{b})$ and DDFS (c and $\mathbf{d}$ ) according to ROR categories for node-negative luminal A HR+/HER2patients with no adjuvant treatment $(\mathbf{a}, \mathbf{c})$ or treated with tamoxifen only (b, d). $p$ Values were derived from log-rank tests. Figure S6. Correlation between Ki-67 expression and ROR score for the HR+/HER2- patients. $\rho=0.62, p<0.001$ (Pearson correlation). (ZIP $340 \mathrm{~kb}$ )

Additional file 2: Table S1. Multivariate analysis of DDFS and BCSS for all patients, including PAM50 intrinsic subtypes. (DOC $49 \mathrm{~kb}$ )

\section{Abbreviations}

ABCSG: Austrian Breast and colorectal Cancer Study Group; ATAC: Arimidex, Tamoxifen, Alone or in Combination study; BCl: Breast Cancer Index; BCSS: Breast cancer-specific survival; CMF: Cyclophosphamide, methotrexate, fluorouracil; CTS: Clinical Treatment Score; DCIS: Ductal carcinoma in situ; DDFS: Distant disease-free survival; EORTC 10041/BIG 3-04

MINDACT: Microarray in Node-Negative and 1 to 3 Positive Lymph Node Disease May Avoid Chemotherapy trial; EPclin: EndoPredict score; ER: Estrogen receptor; FFPE: Formalin-fixed, paraffin-embedded; HER2: Human epidermal growth factor receptor 2; HR: Hormone receptor; $\mathrm{HHC} 4$ score: Four immunohistochemical markers; mRNA: Messenger RNA; OS: Overall survival; PgR: Progesterone receptor; ROR: Risk of recurrence; RS: Oncotype recurrence score; TAM: Tamoxifen

\section{Acknowledgements}

We thank the patients who participated in the constituent studies. This study was performed in collaboration with NanoString Technologies (Seattle, WA, USA). NanoString Technologies provided the calculation of the ROR scores and Prosigna ${ }^{\oplus}$ risk classification.

\section{Funding}

This work was supported by the South-Eastern Norway Regional Health Authority and the Norwegian Cancer Society.

\section{Availability of data and materials}

The dataset used and analyzed during the present study are available from the corresponding author on reasonable request.

\section{Authors' contributions}

HOO carried out data analysis and drafted the manuscript. EB helped design the study, carried out the histological examination, and drafted the manuscript. RSF carried out the statistical analysis and helped with drafting the manuscript. TGL helped in intrinsic subtype data analysis. MA and MATS were responsible for RNA extraction and analysis. JAK, VNK, GAG, ES, EAW, TS, and HGR helped design the study and drafted the manuscript. BN designed the study, carried out data analysis, and drafted the manuscript. All authors read and approved the final manuscript.

\section{Ethics approval and consent to participate}

The study was approved by the Norwegian Regional Committees for Medical and Health Research Ethics, REC South East (reference 2015/2453). Written consent was obtained from all patients.

\section{Consent for publication}

Not applicable.

\section{Competing interests}

The authors declare that they have no competing interests.

\section{Publisher's Note}

Springer Nature remains neutral with regard to jurisdictional claims in published maps and institutional affiliations.

\section{Author details}

'Division of Cancer Medicine, Department of Oncology, Oslo University Hospital, Postbox 4953 Nydalen, 0424 Oslo, Norway. ${ }^{2}$ Division of Laboratory Medicine, Department of Pathology, Oslo University Hospital, Oslo, Norway. ${ }^{3}$ Oslo Centre for Biostatistics and Epidemiology, Oslo University Hospital, Oslo, Norway. ${ }^{4}$ Department of Cancer Genetics, Institute of Cancer Research, Oslo University Hospital, Oslo, Norway. ${ }^{5}$ Division of Medicine, Department of Clinical Molecular Biology, Akershus University Hospital, Lørenskog, Norway.

${ }^{6}$ Breast and Endocrine Surgery Unit, Division of Cancer Medicine,

Department of Oncology, Oslo University Hospital, Oslo, Norway. ${ }^{7}$ Institute of Clinical Medicine, University of Oslo, Oslo, Norway.

Received: 21 June 2017 Accepted: 23 October 2017 Published online: 14 November 2017

\section{References}

1. Early Breast Cancer Trialists' Collaborative Group (EBCTCG). Effects of chemotherapy and hormonal therapy for early breast cancer on recurrence and 15-year sunvival: an overview of the randomised trials. Lancet. 2005;365(9472):1687-1717.

2. Sorlie T, Perou CM, Tibshirani R, Aas T, Geisler S, Johnsen H, Hastie T, Eisen $M B$, van de Rijn M, Jeffrey SS, et al. Gene expression patterns of breast carcinomas distinguish tumor subclasses with clinical implications. Proc Natl Acad Sci U S A. 2001;98(19):10869-74.

3. Perou CM, Sorlie T, Eisen MB, van de Rijn M, Jeffrey SS, Rees CA, Pollack JR, Ross DT, Johnsen H, Akslen LA, et al. Molecular portraits of human breast tumours. Nature. 2000;406(6797):747-52.

4. Harris LN, Ismaila N, McShane LM, Andre F, Collyar DE, Gonzalez-Angulo AM, Hammond EH, Kuderer NM, Liu MC, Mennel RG, et al. Use of biomarkers to guide decisions on adjuvant systemic therapy for women with early-stage invasive breast cancer: American Society of Clinical Oncology Clinical Practice Guideline. J Clin Oncol. 2016;34(10):1134-50.

5. Coates AS, Winer EP, Goldhirsch A, Gelber RD, Gnant M, Piccart-Gebhart M, Thurlimann B, Senn HJ. Tailoring therapies-improving the management of early breast cancer: St Gallen International Expert Consensus on the Primary Therapy of Early Breast Cancer 2015. Ann Oncol. 2015;26(8):1533-46.

6. Filipits M, Nielsen TO, Rudas M, Greil R, Stoger H, Jakesz R, Bago-Horvath Z, Dietze O, Regitnig P, Gruber-Rossipal C, et al. The PAM50 risk-of-recurrence score predicts risk for late distant recurrence after endocrine therapy in 
postmenopausal women with endocrine-responsive early breast cancer. Clin Cancer Res. 2014;20(5):1298-305.

7. Sestak I, Cuzick J, Dowsett M, Lopez-Knowles E, Filipits M, Dubsky P, Cowens JW, Ferree S, Schaper C, Fesl C, et al. Prediction of late distant recurrence after 5 years of endocrine treatment: a combined analysis of patients from the Austrian Breast and colorectal Cancer Study Group 8 and Arimidex, Tamoxifen Alone or in Combination randomized trials using the PAM50 risk of recurrence score. J Clin Oncol. 2015;33(8):916-22.

8. Cardoso F, van't Veer $\sqcup$, Bogaerts J, Slaets L, Viale G, Delaloge S, Pierga JY, Brain E, Causeret S, DeLorenzi M, et al. 70-Gene signature as an aid to treatment decisions in early-stage breast cancer. N Engl J Med. 2016;375(8):717-29.

9. Sparano JA, Gray RJ, Makower DF, Pritchard KI, Albain KS, Hayes DF, Geyer Jr CE, Dees EC, Perez EA, Olson Jr JA, et al. Prospective validation of a 21-gene expression assay in breast cancer. N Engl J Med. 2015;373(21):2005-14.

10. Cuzick J, Dowsett M, Pineda S, Wale C, Salter J, Quinn E, Zabaglo L, Mallon E, Green AR, Ellis IO, et al. Prognostic value of a combined estrogen receptor, progesterone receptor, Ki-67, and human epidermal growth factor receptor 2 immunohistochemical score and comparison with the Genomic Health recurrence score in early breast cancer. J Clin Oncol. 2011;29(32):4273-8.

11. Paik S, Shak S, Tang G, Kim C, Baker J, Cronin M, Baehner FL, Walker MG, Watson D, Park T, et al. A multigene assay to predict recurrence of tamoxifentreated, node-negative breast cancer. N Engl J Med. 2004;351(27):2817-26.

12. Filipits $M$, Rudas $M$, Jakesz R, Dubsky P, Fitzal F, Singer CF, Dietze O, Greil R, Jelen A, Sevelda P, et al. A new molecular predictor of distant recurrence in ER-positive, HER2-negative breast cancer adds independent information to conventional clinical risk factors. Clin Cancer Res. 2011;17(18):6012-20.

13. Zhang Y, Schnabel CA, Schroeder BE, Jerevall PL, Jankowitz RC, Fornander T, Stal O, Brufsky AM, Sgroi D, Erlander MG. Breast Cancer Index identifies early-stage estrogen receptor-positive breast cancer patients at risk for early- and late-distant recurrence. Clin Cancer Res. 2013;19(15):4196-205.

14. Gnant M, Filipits M, Greil R, Stoeger H, Rudas M, Bago-Horvath Z, Mlineritsch B, Kwasny W, Knauer M, Singer C, et al. Predicting distant recurrence in receptor-positive breast cancer patients with limited clinicopathological risk: using the PAM50 risk of recurrence score in 1478 postmenopausal patients of the ABCSG-8 trial treated with adjuvant endocrine therapy alone. Ann Oncol. 2014;25(2):339-45.

15. Dowsett M, Sestak I, Lopez-Knowles E, Sidhu K, Dunbier AK, Cowens JW, Ferree S, Storhoff J, Schaper C, Cuzick J. Comparison of PAM50 risk of recurrence score with oncotype DX and IHC4 for predicting risk of distant recurrence after endocrine therapy. J Clin Oncol. 2013;31(22):2783-90.

16. Parker JS, Mullins M, Cheang MC, Leung S, Voduc D, Vickery T, Davies $S$, Fauron $\mathrm{C}, \mathrm{He}$ X, Hu Z, et al. Supervised risk predictor of breast cancer based on intrinsic subtypes. J Clin Oncol. 2009;27(8):1160-7.

17. Sestak I, Buus R, Cuzick J, Dubsky P, Kronewett R, Ferree S, Sgroi D, Schnabel C, Baehner R, Mallon E, et al. Comprehensive comparison of prognostic signatures for breast cancer in TransATAC [abstract]. Cancer Res. 2017;77(4 Suppl):Abstract S6-05.

18. Synnestvedt M, Borgen E, Russnes HG, Kumar NT, Schlichting E, Giercksky KE, Karesen R, Nesland JM, Naume B. Combined analysis of vascular invasion, grade, HER2 and Ki67 expression identifies early breast cancer patients with questionable benefit of systemic adjuvant therapy. Acta Oncol. 2013;52(1):91-101.

19. Wallden B, Storhoff J, Nielsen T, Dowidar N, Schaper C, Ferree S, Liu S, Leung S, Geiss G, Snider J, et al. Development and verification of the PAM50-based Prosigna breast cancer gene signature assay. BMC Med Genet. 2015;8:54.

20. Nielsen T, Wallden B, Schaper C, Ferree S, Liu S, Gao D, Barry G, Dowidar N, Maysuria M, Storhoff J. Analytical validation of the PAM50-based Prosigna Breast Cancer Prognostic Gene Signature Assay and nCounter Analysis System using formalin-fixed paraffin-embedded breast tumor specimens. BMC Cancer. 2014;14:177.

21. Wiedswang G, Borgen E, Karesen R, Kvalheim G, Nesland JM, Qvist H, Schlichting E, Sauer T, Janbu J, Harbitz T, et al. Detection of isolated tumor cells in bone marrow is an independent prognostic factor in breast cancer. J Clin Oncol. 2003;21(18):3469-78.

22. Wuerstlein R, Sotlar K, Gluz O, Otremba B, von Schumann R, Witzel I, Schindlbeck C, Janni W, Schem C, Bauerfeind I, et al. The West German Study Group Breast Cancer Intrinsic Subtype study: a prospective multicenter decision impact study utilizing the Prosigna assay for adjuvant treatment decision-making in estrogen-receptor-positive, HER2-negative early-stage breast cancer. Curr Med Res Opin. 2016;32(7):1217-24.
23. Barcenas $\mathrm{CH}$, Raghavendra A, Sinha AK, Syed MP, Hsu L, Patangan Jr MG, Chavez-MacGregor M, Shen Y, Hortobagyi GH, Valero V, et al. Outcomes in patients with early-stage breast cancer who underwent a 21-gene expression assay. Cancer. 2017;123(13):2422-31.

24. Albain KS, Barlow WE, Shak S, Hortobagyi GN, Livingston RB, Yeh IT, Ravdin P, Bugarini R, Baehner FL, Davidson NE, et al. Prognostic and predictive value of the 21-gene recurrence score assay in postmenopausal women with node-positive, oestrogen-receptor-positive breast cancer on chemotherapy: a retrospective analysis of a randomised trial. Lancet Oncol. 2010;11(1):55-65.

25. Gnant M, Sestak I, Filipits M, Dowsett M, Balic M, Lopez-Knowles E, Greil R, Dubsky $\mathrm{P}$, Stoeger $\mathrm{H}$, Rudas $\mathrm{M}$, et al. Identifying clinically relevant prognostic subgroups of postmenopausal women with node-positive hormone receptor-positive early-stage breast cancer treated with endocrine therapy: a combined analysis of ABCSG-8 and ATAC using the PAM50 risk of recurrence score and intrinsic subtype. Ann Oncol. 2015;26(8):1685-91.

26. Nielsen TO, Parker JS, Leung S, Voduc D, Ebbert M, Vickery T, Davies SR, Snider J, Stijleman IJ, Reed J, et al. A comparison of PAM50 intrinsic subtyping with immunohistochemistry and clinical prognostic factors in tamoxifen-treated estrogen receptor-positive breast cancer. Clin Cancer Res. 2010;16(21):5222-32.

27. Gluz O, Nitz UA, Christgen M, Kates RE, Shak S, Clemens M, Kraemer S, Aktas B, Kuemmel S, Reimer T, et al. West German Study Group Phase III PlanB Trial: first prospective outcome data for the 21-gene recurrence score assay and concordance of prognostic markers by central and local pathology assessment. J Clin Oncol. 2016;34(20):2341-9.

28. Nasjonalt Servicemiljø for Medisinske Kvalitetsregistre. Årsrapporter for 2015. Trondheim, Norway: Nasjonalt Servicemiljø for Medisinske Kvalitetsregistre. https://www.kvalitetsregistre.no/arsrapporter-2015. Accessed 31 May 2017.

29. Naume B, Borgen E, Kvalheim G, Karesen R, Qvist H, Sauer T, Kumar T, Nesland JM. Detection of isolated tumor cells in bone marrow in early-stage breast carcinoma patients: comparison with preoperative clinical parameters and primary tumor characteristics. Clin Cancer Res. 2001;7(12):4122-9.

30. Delahaye L, Drukker CA, Dreezen C, Witteveen A, Chan B, Snel M, Beumer IJ, Bernards R, Audeh MW, van't Veer $L$, et al. A breast cancer gene signature for indolent disease. Breast Cancer Res Treat. 2017;164(2):461-6.

31. Morales L, Neven P, Timmerman D, Christiaens MR, Vergote I, Van Limbergen E, Carbonez A, Van Huffel S, Ameye L, Paridaens R. Acute effects of tamoxifen and third-generation aromatase inhibitors on menopausal symptoms of breast cancer patients. Anticancer Drugs. 2004;15(8):753-60.

32. Perez EA. Safety profiles of tamoxifen and the aromatase inhibitors in adjuvant therapy of hormone-responsive early breast cancer. Ann Oncol. 2007;18 Suppl 8:viii26-35.

33. Murphy CC, Bartholomew LK, Carpentier MY, Bluethmann SM, Vernon SW. Adherence to adjuvant hormonal therapy among breast cancer survivors in clinical practice: a systematic review. Breast Cancer Res Treat. 2012;134(2): 459-78.

34. Gray RG, Rea D, Handley K, Bowden SJ, Perry P, Earl HM, Poole CJ, Bates T, Chetiyawardana S, Dewar JA, et al. aTTom: long-term effects of continuing adjuvant tamoxifen to 10 years versus stopping at 5 years in 6,953 women with early breast cancer [abstract]. J Clin Oncol. 2013;31(18 Suppl):5.

35. Davies C, Pan H, Godwin J, Gray R, Arriagada R, Raina V, Abraham M, Medeiros Alencar VH, Badran A, Bonfill X, et al. Long-term effects of continuing adjuvant tamoxifen to 10 years versus stopping at 5 years after diagnosis of oestrogen receptor-positive breast cancer: ATLAS, a randomised trial. Lancet. 2013;381(9869):805-16.

36. Sgroi DC, Sestak I, Cuzick J, Zhang Y, Schnabel CA, Schroeder B, Erlander MG, Dunbier A, Sidhu K, Lopez-Knowles E, et al. Prediction of late distant recurrence in patients with oestrogen-receptor-positive breast cancer: a prospective comparison of the breast-cancer index $(B C I)$ assay, 21-gene recurrence score, and IHC4 in the TransATAC study population. Lancet Oncol. 2013;14(11):1067-76.

37. Dubsky P, Brase JC, Jakesz R, Rudas M, Singer CF, Greil R, Dietze O, Luisser I, Klug E, Sedivy R, et al. The EndoPredict score provides prognostic information on late distant metastases in ER+/HER2- breast cancer patients. Br J Cancer. 2013;109(12):2959-64.

38. Sestak I, Zhang Y, Schroeder BE, Schnabel CA, Dowsett M, Cuzick J, Sgroi D. Cross-stratification and differential risk by Breast Cancer Index and recurrence score in women with hormone receptor-positive lymph nodenegative early-stage breast cancer. Clin Cancer Res. 2016;22(20):5043-8. 
39. Sanft T, Aktas B, Schroeder B, Bossuyt V, DiGiovanna M, Abu-Khalaf M, Chung G, Silber A, Hofstatter E, Mougalian S, et al. Prospective assessment of the decision-making impact of the Breast Cancer Index in recommending extended adjuvant endocrine therapy for patients with early-stage ER-positive breast cancer. Breast Cancer Res Treat. 2015;154(3): 533-41.

40. Sestak I, Dowsett M, Zabaglo L, Lopez-Knowles E, Ferree S, Cowens JW, Cuzick J. Factors predicting late recurrence for estrogen receptor-positive breast cancer. J Natl Cancer Inst. 2013;105(19):1504-11.

41. Stein RC, Dunn JA, Bartlett JM, Campbell AF, Marshall A, Hall P, Rooshenas L, Morgan A, Poole C, Pinder SE, et al. OPTIMA prelim: a randomised feasibility study of personalised care in the treatment of women with early breast cancer. Health Technol Assess. 2016;20(10).

42. Tryfonidis K, Poncet C, Slaets L, Viale G, de Snoo F, Aalders K, Van't Veer L, Rutgers E, Piccart M, Bogaerts J, Cardoso F. Not all small node negative (pT1abNo) breast cancers are similar: outcome results from an EORTC 10041/BIG 3-04 (MINDACT) trial substudy [abstract 1500_PR]. Ann Oncol. 2017;28(Suppl_5):v605-49. doi:10.1093/annonc/mdx440.

43. Bonneterre J, Prat A, Galvan P, Morel P, Giard S. Value of a gene signature assay in patients with early breast cancer and intermediate risk: a single institution retrospective study. Curr Med Res Opin. 2016;32(5):835-9.

44. Martin M, Gonzalez-Rivera M, Morales S, de la Haba-Rodriguez J, GonzalezCortijo L, Manso L, Albanell J, Gonzalez-Martin A, Gonzalez S, Arcusa A, et al. Prospective study of the impact of the Prosigna assay on adjuvant clinical decision-making in unselected patients with estrogen receptor positive, human epidermal growth factor receptor negative, node negative earlystage breast cancer. Curr Med Res Opin. 2015;31(6):1129-37.

45. Dowsett M, Nielsen TO, A'Hern R, Bartlett J, Coombes RC, Cuzick J, Ellis M, Henry NL, Hugh JC, Lively T, et al. Assessment of Ki67 in breast cancer: recommendations from the International Ki67 in Breast Cancer working group. J Natl Cancer Inst. 2011;103(22):1656-64.

46. Mu K, Li L, Yang Q, Yun H, Kharaziha P, Ye DW, Auer G, Lagercrantz SB, Zetterberg A. A standardized method for quantifying proliferation by Ki-67 and cyclin A immunohistochemistry in breast cancer. Ann Diagn Pathol. 2015:19(4):243-8.

\section{Submit your next manuscript to BioMed Central and we will help you at every step:}

- We accept pre-submission inquiries

- Our selector tool helps you to find the most relevant journal

- We provide round the clock customer support

- Convenient online submission

- Thorough peer review

- Inclusion in PubMed and all major indexing services

- Maximum visibility for your research

Submit your manuscript at www.biomedcentral.com/submit

) Biomed Central 